\title{
CARTA DA TERRA PARA CRIANÇAS COMO ESTRATÉGIA DE PROMOÇÃO DA SUSTENTABILIDADE AMBIENTAL
}

\author{
Magnollya Moreno de Araújo Lelis ${ }^{1}$ \\ Môngolla Keyla Freitas de Abreu ${ }^{2}$ \\ Maria Laís dos Santos Leite ${ }^{3}$ \\ Veronica Salgueiro do Nascimento ${ }^{4}$ \\ Suely Salgueiro Chacon ${ }^{5}$
}

Resumo: Mudar a atitude e a percepção da realidade desperta para a mudança de pensamento e ajuda a gerar condições para a criação de sociedades sustentáveis. Partindo dessa premissa, o estudo apresenta e dialoga sobre os princípios da Carta da Terra para Crianças aplicados a uma Escola de Ensino Fundamental do município de Barbalha-CE. Foi usada a abordagem qualitativa por meio da pesquisa-ação, tendo como atividade principal a exposição dialogada dos princípios da Carta. Essa iniciativa promoveu a vivência da Educação Ambiental com os estudantes a partir de temáticas como consumo consciente e respeito com o outro, promovendo a troca de vivências, a reflexão da realidade e das atitudes pelos participantes.

Palavras-chave: Educação Ambiental; Pesquisa-Ação; Carta da Terra; Sustentabilidade; Criança.

\footnotetext{
${ }^{1}$ Enfermeira da ESF- Sítio Lagoa. Mestra em Desenvolvimento Regional Sustentável pela UFCA. E-mail: magnollyamoreno@hotmail.com.

2 Professora da Universidade Estadual do Ceará e Coordenadora Pedagógica do Programa Nacional de Acesso ao Ensino Técnico e Emprego (Pronatec). Mestra em Desenvolvimento Regional Sustentável (PRODER) pela Universidade Federal do Cariri (UFCA). E-mail: abreumongolla@yahoo.com.br

3 Coordenadora de Integração e Articulação com a Comunidade da Pró-Reitoria de Extensão da Universidade Federal do Cariri - UFCA. Mestra em Desenvolvimento Regional Sustentável (PRODER) pela Universidade Federal do Cariri (UFCA). E-mail: lais.leite@ufca.edu.br.

${ }_{4}^{4}$ Professora e Pesquisadora da Universidade Federal do Ceará (UFC). Doutora em Educação pela Universidade Federal do Ceará (UFC). E-mail: vesalgueiro@gmail.com.

5 Professora e Pesquisadora do Centro de Ciências Agrárias da Universidade Federal do Ceará (UFC). Doutora em Desenvolvimento Sustentável pela Universidade de Brasília (UnB). E-mail: suelychacon@gmail.com.
}

revista brasileira educação ambiental 


\section{Introdução}

A Educação Ambiental vem aprofundando as reflexões em torno de sua práxis e ampliando a percepção sobre seus objetivos. Para além de preconizar atitudes que levem à proteção e uso sustentável da natureza, vem também despertando para a necessidade de construirmos sociedades efetivamente sustentáveis.

A rápida transformação do ambiente provocada por atitudes antrópicas irresponsáveis, não observou o cuidado da natureza, priorizando os objetivos eminentemente econômicos. A natureza vem sendo exaurida de forma desregrada sem a reflexão sobre as consequências que essas ações ocasionam para o planeta e para as futuras gerações.

São nítidos os sinais de perda da qualidade de vida, desastres ambientais, escassez de água, deterioração contínua dos ecossistemas e aumento dos índices de violência. Essa percepção estava presente na Conferência sobre o Meio Ambiente e o Desenvolvimento, promovido pela Organizações das Nações Unidas (ONU), em 1992. O encontro, que aconteceu no Rio de Janeiro, ficou conhecido como como Eco-92 ou Cúpula da Terra, e reuniu 173 chefes de Estado e de governo. Nesse encontro foi aprovado um documento, a Agenda 21, que traçava metas e objetivos que levariam o mundo a conquistar o "desenvolvimento sustentável", um compromisso com as gerações futuras.

Nessa mesma ocasião foram aprovados dois documentos relevantes e complementares para uma "sociedade sustentável": a Carta da Terra e o Tratado da Educação Ambiental para as Sociedades Sustentáveis e Responsabilidade Global (GADOTTI, 2008). Além destes, vários registros de discussões e reflexões sobre as questões ambientais no âmbito mundial foram produzidos, a fim de avançar positivamente no desenvolvimento da humanidade de forma justa, equitativa e sustentável.

A Carta da Terra, foco deste estudo, foi desenvolvida com o intuito de conscientizar as pessoas em relação ao mundo em que vivem para que possam ter acesso a uma melhor qualidade de vida, sem desrespeitar o meio ambiente, estabelecendo o equilíbrio entre o homem e a natureza. Ela propõe que os Estados reduzam e eliminem padrões insustentáveis de produção e consumo e promovam políticas demográficas adequadas (GADOTTI, 2001).

As relações entre instituições governamentais responsáveis pela Educação Ambiental caminham juntas para a construção de uma cidadania ambiental sustentável, baseada na participação, justiça social e democracia consciente (MEDINA, 1997).

Considerando esses objetivos, o ambiente escolar é de fundamental relevância para a implementação de ações de Educação Ambiental, voltadas ao fortalecimento da capacidade de decisão individual e às práticas de saúde e autocuidado. 
A escola tem um papel primordial (VIEIRA et. al, 2008; CÓRDULA, 2013; ALMEIDA, 2007), com um processo de reconhecimento de valores, em que boas práticas pedagógicas culminam no comprometimento e respeito ao meio ambiente. Córdula (2010, p. 130) complementa ao afirmar que "as escolas são responsáveis por promover nas crianças propostas, saberes $e$ instrumentos necessários à transformação e serem multiplicadores de boas práticas, condutas e pensamentos socioambientais", formando cidadãos conscientes de seu papel na sociedade.

Assim, a escolha em abordar a Carta da Terra para Crianças se baseia na crença de que uma criança orientada e engajada pode ser um novo ator social, implicando em seus padrões de consumo e de comportamento. Desse modo, o objetivo do trabalho é apresentar e dialogar sobre os princípios da Carta da Terra para as Crianças a partir da experiência de uma escola pública municipal no interior do Ceará, sob o olhar da sustentabilidade ambiental.

\section{Educação e Participação Cidadã}

A Educação é uma das formas de preparar o ser humano para estar presente efetivamente em uma sociedade participativa. Isso indica que se necessita de uma educação transformadora, que contribua para promover as mudanças fundamentais exigidas pelos desafios da sustentabilidade, levando a uma participação ativa na busca e aplicação de novos padrões de mudança e organização social (UNESCO, 2005). Participação ativa que requer a construção da consciência crítica a partir de uma educação contextualizada. Segundo Muñoz (2004, p. 9), "participação cidadã é sinônimo de partilha de decisões que afetam a própria vida do indivíduo e da comunidade". Uma vez que o indivíduo é afetado ele também passa a ser conhecedor de tal realidade, podendo intervir com afetividade e sensatez diante da problemática que vier a se instaurar.

Segundo Gadotti (2012), a educação tem um papel essencial no processo de reflexão sobre questões filosóficas fundamentais. $E$ também se propõe a refletir sobre a nossa capacidade de encantamento com o universo, fortalecendo a consciência de que o sentido das nossas vidas não está separado do sentido da existência do próprio planeta. Uma vez que o ser humano percebe-se parte do todo, poderá sentir-se responsável pelas mudanças que almeja presenciar no universo. Porém, promover mudanças requer compromisso, e a primeira condição para que um ser possa assumir um ato empenhado está em ser capaz de agir e refletir (FREIRE, 2003). E tal reflexão pode ser promovida por meio da educação que reconhece e compreende o meio no qual o processo ensino-aprendizagem acontece, reconhece em seu contexto. Segundo Carvalho (2001) o foco de uma educação dentro do novo paradigma ambiental tenderia a compreender, para além de um ecossistema natural, um espaço de relações socioambientais historicamente configurado. 
A Educação contextualizada referenda o princípio político da valorização e articulação dos saberes; além da valorização dos espaços de aprendizagem, tais como o bairro, a comunidade. E esta é regida pela preocupação de não restringir os saberes e os conhecimentos apenas ao ambiente escolar, mas articulá-los com os saberes da vida, em suas diversas dimensões: afetiva, social, prática, estética, cultural (MENEZES; ARAÚJO, 2007). Tal proposta também é alvo da Pedagogia da Vida Cotidiana, a qual trata de uma pedagogia que tenta instigar proposições utópicas, baseada em uma atitude utópica, entendendo a utopia não como aquilo que não é possível, mas como o inédito e viável (MUÑOZ, 2004).

A Educação voltada para o cotidiano do discente também é discutida pela Ecopedagogia, uma pedagogia que promove a aprendizagem a partir do sentido das coisas da vida cotidiana (GUTIÉRREZ; PRADO, 1998). Essa condição é possível, uma vez que o ser humano precisa ser capaz de, estando no mundo, saber-se como parte dele. Se a possibilidade de reflexão sobre si, sobre seu estar no mundo, associada de forma indissolúvel à sua ação sobre o mundo, não existe no ser, seu estar no mundo se reduz a impossibilidade de ultrapassar os limites que lhe são impostos pelo próprio mundo, do que resulta que o ser humano em questão não é capaz de compromisso (FREIRE, 2003).

Quando o sujeito se percebe como parte do universo e assume o compromisso diante deste, a mudança pode acontecer. $\mathrm{E}$ conforme Freire (1999, p. 124), "as relações entre os homens, que não podem ser de dominação nem de transformação, como as anteriores, mas de sujeitos". Isto é, com sujeitos participativos, cidadãos atuantes, será possível promover a mudança na sociedade vigente e para as próximas gerações. Nesse sentido, a Educação para a sustentabilidade, discutida no próximo tópico, corrobora e reforça as premissas discutidas até aqui.

\section{Educação para a Sustentabilidade}

A Educação para o Desenvolvimento Sustentável (EDS) é mais do que a geração de conhecimentos relacionados com a sociedade, o meio ambiente e a economia. A EDS deve direcionar metodologias para a aprendizagem de atitudes, perspectivas e valores que orientam e impulsionam os sujeitos a viverem mais sustentavelmente suas vidas. As crises presenciadas e provocadas pelos seres humanos no planeta mostram, todos os dias, que somos seres irresponsáveis. Educar para o Desenvolvimento Sustentável é educar para que o ser humano tome consciência dessa irresponsabilidade e busque superá-la (GADOTTI, 2012).

Essa discussão foi foco do documento "Década da Educação para o Desenvolvimento Sustentável" (2005-2014), organizado e lançado em 2002 pelas Nações Unidas, cujos objetivos específicos são (GADOTTI, 2012): 
- Facilitar os vínculos e as redes entre os ativistas que defendem a EDS;

- Incrementar ensino-aprendizagem da EDS;

- Colaborar com os países na implementação dos objetivos do Milênio por meio da Educação para o Desenvolvimento Sustentável;

- Oferecer as nações novas oportunidades para incorporar a EDS nos esforços de reforma educacional .

Todos esses objetivos são propostos e discutidos ao longo do documento em questão, com o intuito de promover uma educação direcionada para as necessidades atuais, em especial de um desenvolvimento sustentável.

A EDS não é limitada somente a questão da Educação Ambiental como na maior parcela das discussões, por isso é importante ressaltar que a percepção sobre a construção de cidadãos ambientalmente responsáveis pode levar a uma educação para o meio ambiente como sinônimo de bom comportamento ambiental. Sendo que o problema dessa visão é que ela perde muito da sua condição transformadora quando limita a questão da sustentabilidade à esfera dos comportamentos ambientalmente certos de consciências individuais (CARVALHO, 2008).

Segundo Baptista e Baptista (2005), a perspectiva da educação que se pretende construir, quando o processo escolar é colocado a serviço do desenvolvimento integrado e integral, é de uma escola que trabalha a realidade, constrói conhecimento a serviço do desenvolvimento, especialmente no campo, integra escola, família e comunidade nessa caminhada. Uma escola que acredita que todos são produtores de conhecimento e, consequentemente, sujeitos do processo educacional. O desenvolvimento sustentável que se almeja alcançar com uma educação transformadora, precisa ser "ambientalmente correto, socialmente justo, economicamente viável e culturalmente respeitoso das diferenças" (GADOTTI, 2012, p.57). E a educação para a sustentabilidade busca contribuir com esse objetivo.

Considerando o exposto, o próximo tópico traz a proposta da Carta da Terra como um elemento que pode contribuir para um processo mais amplo e complexo de ensino e aprendizagem, que visa a construção de uma sociedade sustentável a partir da percepção e da ação de cada um.

\section{Carta da Terra para Crianças: uma prática de ensino-aprendizagem em prol da sustentabilidade}

A Carta da Terra pode ser definida como uma declaração de princípios globais para orientar a questão do meio ambiente e do desenvolvimento. Ela inclui os princípios básicos que deverão reger o comportamento da sociedade em relação à economia e ao meio ambiente, para assegurar nosso futuro comum. Para conseguir o desenvolvimento sustentável e melhor qualidade de vida para todos os povos, a Carta da Terra propõe que os Estados reduzam e

revista brasileira educação ambiental 
eliminem padrões insustentáveis de produção e consumo e promovam políticas demográficas adequadas (GADOTTI, 2001).

A Carta fornece um bom exemplo de uma visão integradora dos princípios necessários para a construção de um mundo justo, pacífico e sustentável (UNESCO, 2005). A discussão sobre a Carta da Terra ainda constitui um fator relevante para a construção da cidadania planetária, pois qualquer pedagogia que não vivencie as temáticas e realidades da globalização e do movimento ambiental está fora do contexto mundial. E assim vive-se a segunda globalização, retratada ao longo da Carta da Terra como um novo código de ética universal, e que deveria assim contribuir não apenas como orientação para os Estados sobre como fazer a diferença, mas, sobretudo, pelo impacto que seus princípios podem ter no cotidiano do cidadão (GADOTTI, 2005).

Nessa ótica, o Núcleo de Amigos da Infância e da Adolescência (NAIA) criou em 2002, a Carta da Terra para Crianças. O intuito desta Carta é colaborar com os educadores no momento de diálogo com crianças a respeito dos princípios da Carta da Terra, documento original. Essa proposta foi desenvolvida durante a segunda edição do ForunZinho Social Mundial, quando milhares de crianças apresentaram e discutiram soluções e propostas para transformar o mundo num lugar melhor para se viver. Vale ressaltar que o Forunzinho Social Mundial é uma versão infantil do Fórum Social Mundial, encontro anual que busca elaborar alternativas para transformar socialmente 0 mundo atual.

Ainda sobre a cartilha da Carta da Terra para Crianças, esta foi elaborada com texto de Sílvia Gonçalves, ilustrações de Leandro Bierhals e a organização de Valéria Viana com apoio do Governo do Estado do Rio Grande do Sul - Governo da Administração Popular e UNICEF e publicada em 2002.

O NAIA apresenta os princípios da Carta da Terra para Crianças conforme dispõe o Quadro 1 (próxima página).

A Carta da Terra tem um grande potencial educativo ainda não suficientemente explorado, tanto na educação formal, quanto na não-formal, em função de sua proposta de diálogo intertranscultural, pode contribuir na superação do conflito civilizatório que vivemos na atualidade (GADOTTI, 2012).

Távora (2012), em seu estudo intitulado "Práticas e reflexões sobre a Educação Ambiental na escola pública", concluiu que trabalhar esse tema no contexto escolar estimula a conservação do ambiente por meio de práticas corretas. E que a Educação Ambiental traz à tona valores de amor e respeito à vida, propondo sempre uma reflexão sobre a nossa postura perante as outras pessoas e ao nosso planeta. 
Quadro 1 - Princípios da Carta da Terra para crianças e seu significado.

\begin{tabular}{|c|c|}
\hline Princípios & Significado \\
\hline $\begin{array}{l}\text { Conheça e proteja os animais e as } \\
\text { pessoas }\end{array}$ & $\begin{array}{l}\text { - Respeitar o modo como as plantas, animais e pessoas vivem } \\
\text { (mesmo que lhe pareça estranho ou diferente); } \\
\text { - Lutar contra a matança indiscriminada de animais; } \\
\text { - Cuidar das plantas }\end{array}$ \\
\hline $\begin{array}{l}\text { Sempre respeite a vida de todo ser } \\
\text { humano, o direito das pessoas e o } \\
\text { bem-estar de todos os seres vivos }\end{array}$ & $\begin{array}{l}\text { A vida de todo e qualquer ser vivo deve ser respeitada com } \\
\text { seus direitos garantidos }\end{array}$ \\
\hline $\begin{array}{l}\text { Utilize com cuidado o que a } \\
\text { natureza nos oferece }\end{array}$ & $\begin{array}{l}\mathrm{O} \text { ar, a água, a terra... E defender a ideia de que todos têm } \\
\text { direito a esses bens naturais. }\end{array}$ \\
\hline $\begin{array}{l}\text { Mantenha limpo o lugar onde você } \\
\text { vive }\end{array}$ & $\begin{array}{l}\text { - Economizar água; } \\
\text { - Jogar o lixo no lixo; } \\
\text { - Procurar manter todas as suas coisas em ordem; } \\
\text { - Separar o lixo seco do orgânico; } \\
\text { - Adotar a idéia dos "três erres": Reduzir, Reutilizar e Reciclar. }\end{array}$ \\
\hline $\begin{array}{l}\text { Aprenda mais sobre o lugar onde } \\
\text { você vive }\end{array}$ & $\begin{array}{l}\text { - Sobre os seres vivos que fazem parte da sua comunidade e } \\
\text { dos que vivem em outros lugares do planeta. } \\
\text { - Conhecer e valorize o lugar onde vive e compartilhe com } \\
\text { outros o que você sabe. }\end{array}$ \\
\hline $\begin{array}{l}\text { Todo mundo deve ter o que } \\
\text { necessita para viver }\end{array}$ & $\begin{array}{l}\text { - Não deve existir a miséria. Procurar desejar ter somente o } \\
\text { que realmente precisa. - Aprender a compartilhar o que tem e } \\
\text { defenda sempre que: Todos devem ter o que necessitam para } \\
\text { viver com dignidade; Todas as crianças devem ter acesso à } \\
\text { escola; as pessoas necessitadas devem ser aquelas a quem } \\
\text { nós devemos ajudar mais. }\end{array}$ \\
\hline $\begin{array}{l}\text { Todas as crianças são igualmente } \\
\text { importantes }\end{array}$ & - Todas as crianças devem aprender e crescer juntas; \\
\hline $\begin{array}{l}\text { Sempre defenda a ideia de } \\
\text { qualquer criança; }\end{array}$ & $\begin{array}{l}\text { Seja ela menino ou menina, rico ou pobre, negro ou branco, ou } \\
\text { de qualquer raça, deste ou de outro país, que fale nossa língua } \\
\text { ou não, que independa de religião... }\end{array}$ \\
\hline Diga sim a paz e não a guerra & $\begin{array}{l}\text { - Procurar viver em harmonia com todo mundo; } \\
\text { - Ajudar as pessoas que estão a sua volta e ofereça a elas a } \\
\text { sua amizade; } \\
\text { - Colaborar para que mais pessoas apreciem as coisas boas e } \\
\text { bonitas do nosso planeta; } \\
\text { É preciso que todos se entendam e se ajudem mutuamente. }\end{array}$ \\
\hline $\begin{array}{l}\text { Estude, dando especial atenção } \\
\text { para aquelas coisas que o ajudarão } \\
\text { a conviver melhor com as outras } \\
\text { pessoas e com nosso planeta }\end{array}$ & $\begin{array}{l}\text { - Quanto melhor se educar, melhor saberá viver; } \\
\text { - Utilizar os meios de comunicação para lhe ajudar a } \\
\text { compreender as dificuldades e problemas que as pessoas ao } \\
\text { redor do mundo enfrentam; } \\
\text { - Estudar com maior interesse os assuntos que lhe ajudem a } \\
\text { ser uma pessoa melhor e a buscar alternativas para tornar o } \\
\text { mundo um lugar melhor de se viver. }\end{array}$ \\
\hline
\end{tabular}

Fonte: Elaborada pelas autoras com base na Carta da Terra para Crianças (2002).

Dessa forma, a apresentação e a diálogo acerca da Carta da Terra para Crianças na Escola pode contribuir para formação de atores mais conscientes de suas escolhas e da maneira que estabelece a relação com 0 outro e com o mundo, no presente e no futuro. A partir da construção da consciência crítica, permeada pela educação cidadã, o educando pode ainda ser um multiplicador da ideia e despertar em outras pessoas como pais, 
irmãos, avós, professores, para que valorizem o bem-estar do outro e o consumo consciente, promovendo uma sociedade justa, pacífica e sustentável.

Com base nessas reflexões e descobertas teóricas, o trabalho traz a experiência de utilizar a Carta da Terra como elemento para educação para a sustentabilidade em uma escola pública no interior do Nordeste do Brasil, o que é exposto a seguir.

\section{Aplicando as descobertas teóricas - procedimentos metodológicos}

O trabalho teve como lócus a Escola de Ensino Fundamental Santa Luzia, situada na zona rural do Município de Barbalha, região Cariri do estado do Ceará, Nordeste do Brasil, dista em linha reta $405 \mathrm{Km}$ da capital do estado, Fortaleza (IPECE, 2014) (Figura 1). O município de Barbalha possui segundo o IBGE (2014) uma população estimada em 2014 de 58.347 habitantes distribuídos em idade escolar em 42 escolas, distribuídas na zona rural e urbana.

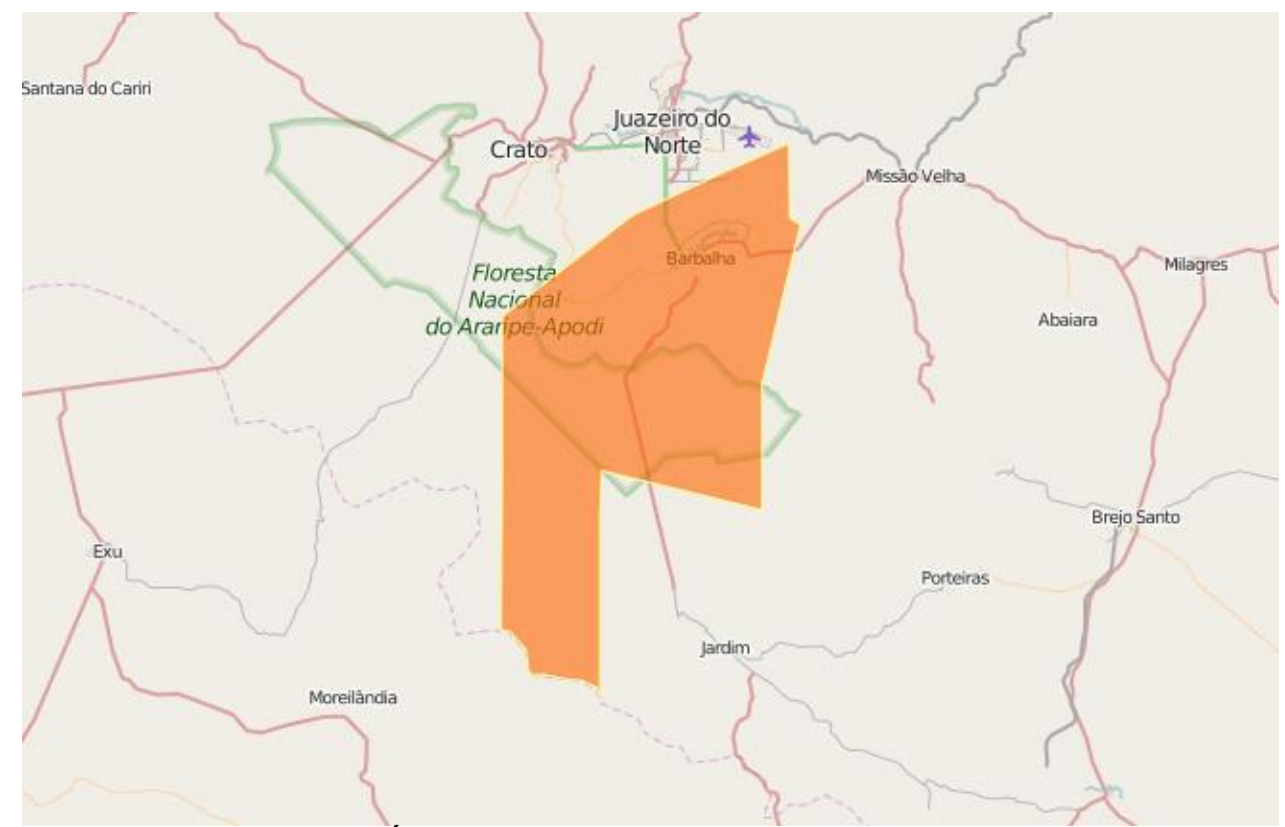

Figura 1: Área representativa da unidade territorial de Barbalha.

Fonte: IBGE, Instituto Brasileiro de Geografia e Estatística.

Este campo de estudo foi escolhido por fazer parte da área de abrangência da Estratégia de Saúde da Família onde atua uma das autoras deste estudo, uma vez que esta já conhecia a realidade da escola, os professores e diretores, facilitando o desenvolvimento do estudo. Os participantes foram os alunos da turma $4^{\circ}$ ano do Ensino Fundamental. Vale destacar que a escola só tem uma turma de tal ano e que esta série foi selecionada em virtude do conhecimento prévio sobre meio ambiente e seres vivos, de acordo com o programa curricular previsto pela escola. 
A presente pesquisa foi desenvolvida inicialmente por uma pesquisa bibliográfica sobre conteúdos relacionados à Carta da Terra para Crianças e Educação para a Sustentabilidade ambiental, visando a apresentação da Carta da Terra adaptada para o público infantil e as discussões a partir desta, correlacionando ao cotidiano dos discentes. Além destas etapas seguiu-se a pesquisa de caráter qualitativo com a metodologia da pesquisa-ação para auxiliar a coleta de dados iniciada por meio da pesquisa bibliográfica, os dados ao final foram analisados e discutidos por meio da análise de conteúdo.

É importante que se compreenda a pesquisa-ação como um dos diversos tipos de investiga-ação, termo que define qualquer processo que se cumpra através de um ciclo no qual se aprimora a prática com alternâncias entre agir no campo da prática e investigar a respeito dela, na busca por avanços na prática, aprendendo mais ao longo do processo. A pesquisa-ação educacional é uma estratégia para o desenvolvimento de pesquisadores e professores de tal forma que eles possam utilizar suas pesquisas para aperfeiçoar a prática de ensino e, consequentemente o aprendizado de seus alunos (TRIPP, 2005).

Por meio da análise de conteúdo os dados foram discutidos e analisados, pois segundo Bardin (2011), o termo análise de conteúdo designa um conjunto de técnicas de análise das comunicações visando a obter, por procedimentos sistemáticos e objetivos de descrição do conteúdo das mensagens, indicadores que permitam a inferência de conhecimentos relativos às condições de produção/recepção destas mensagens.

A pesquisa bibliográfica foi iniciada em agosto de 2014 a partir dos conteúdos da disciplina de Educação para a sustentabilidade do Programa de Pós-Graduação em Desenvolvimento Sustentável (PRODER), da Universidade Federal do Cariri (UFCA), ao qual as autoras estavam vinculadas. No mês de outubro de 2014 realizou-se o planejamento da Pesquisa-ação e contatos com a Escola de Ensino Fundamental Santa Luzia, o que permitiu a realização da atividade tendo por base a Carta da Terra para Crianças.

Os encontros aconteceram nos dias 28 de novembro e 02 de dezembro do mesmo ano, todos no ambiente escolar, especificamente na sala de aula específica dos sujeitos desta pesquisa. Consistiram em um momento inicial de apresentação pessoal entre os sujeitos envolvidos por meio de dinâmicas de grupo, seguido da explanação do panfleto Carta da Terra para Crianças, com diálogos entre as autoras deste trabalho e os estudantes. Após esse momento, seguimos com apresentação de vídeos e construção de desenhos individuais e coletivos, com uso de lápis, pincéis, cartolinas e folhas de papel ofício, a fim de possibilitar aos discentes que demonstrassem pensamentos e sentimentos relacionados ao que foi discutido anteriormente.

O momento foi finalizado com um registro fotográfico do grupo e os agradecimentos aos envolvidos, de forma mais direta, em toda a pesquisa. $\mathrm{O}$ trabalho não foi encerrado nesse ambiente, pois posteriormente foram 
discutidos os dados observados e coletados a partir da intervenção, na perspectiva de relacioná-los mais uma vez com estudos bibliográficos.

\section{Percebendo as conexões - Resultados e discussão}

As atividades foram planejadas no mês outubro de 2014 e deveriam acontecer em dois momentos. O primeiro momento aconteceu para criar um vínculo com os pesquisados e conhecer a realidade em que vivem, no segundo buscou-se apresentar os princípios da Carta da Terra, de forma lúdica e dinâmica. O primeiro encontro do dia 28 de novembro de 2014 iniciou-se às 7 horas estendendo-se até às 9 horas, com a apresentação da proposta de forma sucinta para os alunos, seguida de uma dinâmica de apresentação do grupo.

Os estudantes residem nas proximidades da escola compartilhando assim escola, estudantes e familiares dos mesmos benefícios e danos sofridos pelos mais diversos fatores, externos e internos. A partir desta realidade, as discussões seguiram os princípios da Carta da Terra de acordo com temáticas que afetam as crianças e demais residentes da comunidade, tanto no que se refere ao ambiente escolar quanto de sua residência familiar. Foram mencionados exemplos do cotidiano onde foram indagadas suas opiniões sobre o assunto, envolvendo cuidados com outros seres vivos e com o ser humano, bem como sobre a natureza e seu uso de forma consciente.

Ao longo das exposições e discussões as crianças foram participando e possibilitando a continuidade das propostas anteriormente pensadas. Deu-se continuidade a proposta solicitando que fosse elaborado um desenho individual com tema livre relacionado ao que foi discutido anteriormente. Finalizou-se com a apresentação e comentários sobre os desenhos.

No dia 02 de dezembro do mesmo ano às 7 horas da manhã teve início o segundo momento, quando foi desenvolvida uma exposição dialogada sobre os princípios da Carta da Terra, utilizando recursos didáticos variados, a fim de tornar a atividade mais dinâmica, didática e mais participativa. A etapa seguinte consistiu na produção de desenho coletivo tendo como tema "o que aprendemos ao longo dos nossos diálogos sobre a Carta da Terra para Crianças?" Logo após, o desenho foi apresentado sendo comentado pelos participantes. As 11 horas a atividade foi finalizada com a entrega de um panfleto resumido e didático sobre os princípios da Carta da Terra.

A proposta pedagógica de solicitar às crianças que nos apresentassem suas percepções sobre 0 cotidiano no que se refere às condições socioambientais, bem como sobre sua compreensão sobre os princípios da Carta da Terra para Crianças, por meio de desenhos, visava instigar ainda mais a construção de uma autonomia no pensar, bem como a manifestação da consciência crítica. Segundo Freire (1979) o desenvolvimento da consciência crítica deve ser viabilizado através do processo educativo, o que ocorre somente por meio do exercício da reflexão crítica a respeito da realidade social, 
marcada pela análise profunda desta. Desta forma, o indivíduo constitui-se como sujeito, ativo e transformador da história.

Ao passo que os estudantes divulgavam suas percepções aos demais colegas, geravam inquietações, que representavam tanto concordâncias como discordâncias, sobre o que estava sendo exposto. Permitindo assim a construção coletiva sobre a temática central, sem impossibilitar a apropriação do discente de uma criticidade necessária para o exercício da cidadania, proposta foco da educação básica.

Observou-se que foi de suma importância a divisão em dois encontros, para que pudéssemos criar um vínculo com os alunos e compreendermos a realidade em que estão inseridos. Conforme Gadotti (2001), o Desenvolvimento Sustentável tem um componente educativo formidável: a preservação do meio ambiente depende de um processo de conscientização ecológica e a formação da consciência depende da educação, seja ela formal ou informal. Tal condição é abordada pela ecopedagogia, uma pedagogia para a promoção da aprendizagem do sentido das coisas a partir da vida cotidiana.

A partir da ecopedagogia encontramos o sentido ao caminhar, vivenciando o contexto e o processo para abrir novos caminhos; não somente observando o caminho. Foi a partir das percepções da ecopedagogia que observamos a importância do desejo de falar, de participar e de contribuir, demostrado pela maioria dos estudantes, sendo possível interagir com a turma e trazer historias cotidianas que vivenciam diariamente como a violência, 0 desmatamento, os maus tratos com seres humanos e animais, a poluição do ar, o uso irracional de água e despertar para a possibilidade de mudança. Mudança para um mundo melhor com harmonia, paz, amor, união, respeito pelos outros e pelo meio ambiente.

Os desenhos confirmaram o que havia sido posto no momento das falas. Os estudantes retrataram no desenho individual a visão que possuem sobre o mundo poluído e agressivo em que vivem atualmente, especialmente no bairro onde moram. Observamos que apesar da pouca idade, eles conseguiram identificar que males podem advir se essa realidade não for mudada e que a transformação pode partir de cada um. $\mathrm{O}$ desenho coletivo permitiu perceber alguns critérios importantes, como o respeito pelo outro, cuidado com o meio ambiente, a importância da separação correto do lixo, a promoção da paz e não da guerra, o uso correto da água e o cuidado com os animais. Tendo alguns desenhos que se destacaram, tal como um coração feito por uma discente que finalizou dizendo que com amor tudo se resolveria!

Todas as observações e discussões feitas ao longo deste trabalho corroboram com os conceitos anteriormente estudados e agora vistos sob a ótica da práxis, em especial sobre a Educação para o Desenvolvimento Sustentável, que é mais do que uma base de conhecimentos interligados ao meio ambiente, a economia e a sociedade. A EDS deve ocupar-se da aprendizagem de práticas, perspectivas e valores que orientam e estimulam as pessoas a viverem de forma mais sustentável suas vidas (GADOTTI, 2012). 
Com o desenvolvimento das atividades buscamos o comprometimento dos estudantes, pois conforme Freire (2003) é justamente esta capacidade de atuar, operar, de transformar a realidade de acordo com finalidades almejadas pelo homem, que está associada à sua capacidade de refletir, que o faz um ser da práxis.

Sobre a avaliação do desempenho do projeto, esta foi feita de forma contínua, desde o contato inicial até a finalização da pesquisa. Após a apresentação, análise e interpretação dos dados, percebemos que, por meio da participação dos estudantes e da construção do desenho coletivo, eles sentem a necessidade de mudança de hábitos, práticas e atitude para que tenhamos um mundo melhor, onde se viva com mais amor ao próximo e ao meio ambiente.

\section{Considerações Finais}

A Carta da Terra é desafiadora ao estimular o exame de valores e a escolha de um futuro melhor. Desperta para um chamado em busca de um terreno comum em meio à diversidade a fim de obtermos visão ética compartilhada por uma quantidade crescente de pessoas em muitas nações e culturas ao redor do mundo. Diante disso, a intervenção pedagógica e a pesquisa promoveram a vivência dos estudantes com a temática Educação Ambiental, bem como a inserção de temáticas ligadas ao contexto no qual estão inseridos.

As temáticas que envolvem meio ambiente, práticas conscientes de consumo, cuidado e respeito com o outro, além de proporcionarem a prática da educação contextualizada, incentivaram os estudantes a refletirem com criticidade sobre o mundo atual. Uma vez que têm a visão reflexiva sobre o meio que o cercam, acredita-se e espera-se que os estudantes passem a buscar uma vida mais sustentável, contemplando o objetivo deste estudo.

A participação dos estudantes em cada etapa desenvolvida do projeto permitiu conhecer a realidade da comunidade escolar Santa Luzia, além de proporcionar reflexões sobre práticas enquanto docentes e discentes que somos. As informações compartilhadas pelos estudantes ao serem relacionadas com os princípios da Carta da Terra tornam a aprendizagem mais significativa e instigam as novas competências e habilidades em cada um dos envolvidos. Assim, a partir de um novo olhar a comunidade local passa a exercer a cidadania planetária de forma mais efetiva e constante.

\section{Agradecimentos}

Ao Programa de Pós-Graduação em Desenvolvimento Regional Sustentável da Universidade Federal do Cariri-UFCA pela vivência intensa e rica em aprendizados. À CAPES - Coordenação de Aperfeiçoamento de Pessoal de Nível Superior pelo auxílio financeiro a parte das autoras durante 0 período do Mestrado. 


\section{Referências}

ALMEIDA, M. A criança é agente multiplicador contra o desperdício. Site Mercado Ético- Sua Plataforma para a Sustentabilidade. Out, 2007. Disponível em: <http://maua.br/files/monografias/completo-educacaoambiental-crianca-como-agente-multiplicador-280830.pdf> Acesso em out de 2016.

BAPTISTA, F.M.C.; BAPTISTA, N.. (Org.). Educação Rural: sustentabilidade do campo. 2ª ed.. Feira de Santana, BA: MOC; UEFS; (Pernambuco): SERTA, 2005.

BARDIN, L. Análise de conteúdo. São Paulo: 2011, Edições 70.

CARVALHO, I.C.M. Educação para sociedades sustentáveis e ambientalmente justas. Rev. eletrônica Mestr. Educ. Ambient. ISSN 1517-1256, v. especial, dezembro de 2008.2 Disponível em<http://www.seer.furg.br/remea/article/viewFile/3387/2033> Acesso em nov de 2014.

CARVALHO, I.C.M. Qual Educação Ambiental? Elementos para um debate sobre Educação Ambiental e extensão rural. Agroecologia e Desenvolvimento Rural Sustentável, Porto Alegre, v.2, n.2, abr./jun.2001. Acesso em nov de 2014.

CÓRDULA, E.B.L. A (trans) formação socioambiental do educando: o papel do professor, da família e da sociedade na escola. Revista Meio Ambiente e Sustentabilidade. vol.3 n.2 | jan/jun 2013. Disponível em: <file:///C:/Users/oi/Downloads/84-578-1-PB.pdf>. Acesso em: out de 2016.

CÓRDULA, E.B.L. Educação Ambiental Integradora. Cabedelo-PB: EBLC, 2010 [CD-ROM].

FREIRE, P. Educação como prática da liberdade. $23^{a}$ ed. Rio de Janeiro: Paz e Terra, 1999.

FREIRE, P. Educação e Mudança. Editora Paz e Terra S/A. São Paulo, 2003.

FREIRE, P. Pedagogia da Autonomia: saberes necessários à prática

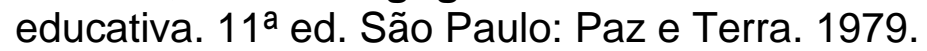

GADOTTI, M. Educar para a Sustentabilidade. Inclusão Social, Brasília, v. 3, n. 1, p. 75-78, out. 2007/mar. 2008. Disponível em:< http://revista.ibict.br/inclusao/article/view/1624/1830> Acesso em jun de 2015.

GADOTTI, M. Educar para a sustentabilidade: uma contribuição à década da educação para o desenvolvimento sustentável. 2. ed. São Paulo: editora e livraria Instituto Paulo Freire, 2012. - (Série Unifreire; 2).

GADOTTI, M. Pedagogia da terra e cultura de sustentabilidade. Revista Lusófona de Educação, p.15-29, junho de 2005.

GADOTTI, M. A Carta da Terra na Educação. São Paulo: Editora e Livraria Instituto Paulo Freire, 2010. -- (Cidadania planetária: 3). 
GUTIÉRREZ, F.; PRADO, C. Ecopedagogia e cidadania planetária. São Paulo: Cortez, 1989.

IBGE - INSTITUTO BRASILEIRO DE GEOGRAFIA E ESTATÍSTICA. Disponível em: <http://cidades.ibge.gov.br/xtras/perfil.php?codmun=230190> Acesso em: jul de 2015.

IPECE - INSTITUTO DE PESQUISA E ESTRATÉGIA ECONÔMICA DO CEARÁ. Perfil Básico do Municipal 2014 Barbalha. Disponível em: $<$ http://www.ipece.ce.gov.br/publicacoes/perfil basico/pbm-2014/Barbalha.pdf> Acesso em jul de 2015.

MEDINA, N.M. Breve Histórico da Educação Ambiental. In: PADUA, S.M.; TABANEZ M.F. (org.). Educação Ambiental caminhos trilhados no Brasil. Brasília: Instituto e Pesquisas Ecológicas, 1997; p. 265-269.

MENEZES, A.C.; ARAÚJO, L.M. Currículo, contextualização e complexidade: espaço de interlocução de diferentes saberes. In: Currículo, contextualização e complexidade: Elementos para se pensar a escola no Semi-Árido. JuazeiroBA: Selo Editorial da RESAB. 2007, p. 33-4

MUÑOZ, C. Pedagogia da Vida Cotidiana e Participação Cidadã. São Paulo: Editora Cortez. Guia da Escola Cidadã. Instituto Paulo Freire. 2004.

SAUVÉ, L. Educação Ambiental: possibilidades e limitações. Educação e Pesquisa, São Paulo, v. 31, n. 2, p. 317-322, maio/ago. 2005.

TÁVORA, M. A. Práticas e reflexões sobre a Educação Ambiental na escola pública. Revbea, Rio Grande, v. 7, p. 37-43, 2012.

TRIPP, D. Pesquisa-ação: uma introdução metodológica. Educação e Pesquisa, São Paulo, v. 31, n. 3. p. 443-466, set./dez. 2005.

UNESCO. Década das Nações Unidas da Educação para o Desenvolvimento Sustentável (2005-2014). Brasília: UNESCO, 2005.

VIEIRA, S.R. A Educação Ambiental e o currículo escolar. Rev. Espaço Acadêmico, n. 83, Abr, 2008. Disponível em: <http://www.espacoacademico.com.br/083/83vieira.htm> Acesso em: 10/2016. 